\title{
The Inclusion of Students with Visual Impairment at Addis Ababa University, Ethiopia: Challenges and Prospects
}

\author{
Teferi Adnew Zelelew
}

Department of Inclusive Education, Debre Berhan University, Ethiopia

Copyright $\subseteq 2018$ by authors, all rights reserved. Authors agree that this article remains permanently open access under the terms of the Creative Commons Attribution License 4.0 International License

\begin{abstract}
Following the introduction of Special Needs Education Program Strategy that Ethiopian government developed in 2006, all public HEIs have been required to implement inclusive education as a mandatory approach when educating students with impairment, including those who are visually impaired. However, the actual implementation of an inclusive approach is being challenged by the social, political and physical circumstances of higher education institutions. Therefore, this study aimed at examining the existing challenges and prospects towards the inclusion of students with Visual Impairment (VI) in the particular context of Addis Ababa University (AAU). The study adopted an interpretive paradigm for deeper understanding of the inclusion of students with VI at AAU and informing the detailed judgments made by experts of a suggested action plan to progressively provide support for students with VI at AAU. The study also applied the critical disability paradigm as a complementary philosophical base in order to examine critically the challenges that students with VI face and to suggest ways to transform the inclusive policies and practices of AAU in favor of the students. The researcher undertook the qualitative case study and a Delphi design to address the main aim of this research (i.e., to determine how best to implement an action plan that progressively increases support for students with VI at AAU over a period of time). The action plan that comprises various support measures and the necessary resources was developed using the empirical results of this study as well as the existing findings and best practices found in the literature study. It was scrutinized and approved by a number of experts to be implemented over the next five years at AAU in order to improve the support provided to students with VI.
\end{abstract}

Keywords Inclusion, Inclusive Education, Impairment, Students with Visual Impairment, Higher Education Institutions, Challenges, Prospects, Delphi Method, Support Measures, Action Plan

\section{Introduction}

\subsection{Background and Statement of the Problem}

Having worked as a special needs education instructor and vice-president at a university in Ethiopia for the past eight years, the researcher realized that the inclusion of students with VI has been complicated by several factors regarding the policies and practices of Higher Education Institutions (HEIs). For example, Ethiopian universities still accept students with VI only in certain fields of study (namely Social Science and Humanities). This practice limits the access to several fields that students with VI need to study. According to United Nations conventions, all governments are currently required to ensure the rights and equal opportunities of peoples with impairments through the collaborative efforts of policy makers, practitioners, people with impairments and their associations (Mji, MacLachlan, Melling- Williams \& Gcaza, 2009:1).[1] As the role of teacher education is vital for HEIs to ensure equal opportunities for learners with diverse needs (Opertti, Brady \& Duncombe, 2009:209;[2] Quality Assurance Agency (QAA), 2010:11[3]), all university staff need extensive training in inclusive education (Sapon-Shevin, 2007:100). [4]) Especially, the Ethiopian Ministry of Education/MoE (2006:24, 25)[5] requires all teachers of students with VI to have a good understanding of the principles of inclusive education by incorporating introductory courses in special needs education in the regular teacher training program since 2006. At the university where the research was conducted, however, there are many academic staff members who obtained their professional qualifications before the introduction of the strategy. Bearing this in mind, the researcher believes that the majority of lecturers at AAU do not know how to 
support students with VI in inclusive settings.

In addition, most of the facilities at AAU were built 50 years ago; this means that progressive changes in the buildings need to be made to meet the special needs of students with VI (Higher Education Relevance and Quality Agency, 2009:7).[6] Under these circumstances it might be difficult for the university to create an accessible inclusive learning environment for students with VI. At the same time, Ethiopian universities and lecturers expect students with VI to cope with the existing structures, instead of making adjustments to adapt them to the students' needs (MoE, 2006:i).[5] As a result, the drop-out rate is becoming a critical problem at the university (MoE, 2006:5[5]; Saint, 2004:92[7]). Reducing educational wastage requires the development of support systems in inclusive HEIs (MoE, 2006:28, 30).[5] However, Ethiopian universities have been admitting students with VI without the provision of organized support. Since there is no organized form of support to accommodate them at AAU, students with VI encounter several challenges in their pursuit of higher education. Opertti, Brady and Duncombe (2009: 212)[2] note that identifying and removing educational, social and cultural barriers to participation and learning is a key feature of inclusive education. As an inclusive approach is considered to be the new trend in Ethiopian universities, the identification and removal of barriers to inclusion and participation of all learners with significant impairments has become the central point of this approach and its implementation (MoE, 2006:1[5]; Saint, 2004:107).[7] To this end, the Ethiopian Ministry of Education has encouraged HEIs to conduct studies about the current status and main issues of inclusive education at all levels of schooling (MoE, 2006:6, 12,17,21,23).[5] If Ethiopian HEIs do not overcome these challenges, their shift towards inclusion might be reversed.

In order to contribute to the body of knowledge on the topic of inclusion in Ethiopian universities, this study focuses on the identification of potential solutions for the existing challenges at AAU. The rationale for this research is that unless a critical analysis of the prevailing challenges is made and a set of intervention strategies is devised, it will be very difficult to ensure successful inclusive education for students with VI at HEIs. One of the most important actions envisaged in this study is the establishment of support structures for students with VI at AAU. This is because the need for developing an action plan that incorporates practical guidelines to establish these support systems and improve its inclusive educational practices is vital for the university. As a result the research problem of this study focuses on existing challenges experienced by students with VI, and the development of an action plan to better support them at AAU. Taking this into account, the researcher formulated the following research questions for this study:

\section{Primary Research Question}

How best can an action plan be implemented over a period of five years to progressively increase the support for students with VI at Addis Ababa University (AAU)?

\section{Secondary Research Questions}

To answer the above question, the following secondary or sub-questions were formulated for this study:

1. What are the challenges that students with VI face at AAU?

2. What resources (human, physical and financial) are necessary to provide effective support for students with VI?

3. What solutions are available for AAU to overcome the challenges or barriers that students with VI face?

4. What is the best way in which such a plan can be developed for AAU?

\subsection{Aims of the Research}

The research aims for this study can therefore be formulated as follows:

\section{Primary Research Aim}

To determine how best an action plan can be implemented over a period of five years to increase progressively the support for students with VI at AAU.

\section{SecondaryAims}

In order to achieve the primary aim and to execute the research plan, the following secondary aims of the primary aim were formulated:

- To identify the challenges or barriers that students with VI experience at AAU;

- To explore the resources that are necessary to provide effective support for students with VI at AAU;

- To determine solutions to overcome challenges that students with VI face at AAU;

- To determine the best way to develop the most appropriate action plan to overcome the challenges and barriers for students with VI.

\subsection{Demarcation of the Study}

This study focused on the inclusion of students with VI only; no other impairments were considered. A detailed analysis was made of a single public university in Ethiopia, which is referred to as Addis Ababa University (AAU). This university was selected because it has had many years of experience in admitting many students with VI to degree programs. Of all the students enrolled in inclusive programs offered at AAU, the study focused on under-graduate students only.

As the researcher preferred to use experts who know the circumstances of AAU, the number of participants in the Delphi investigation was restricted to seven owing to the limited number of experts who have $\mathrm{PhD}$ in the area of 
special needs education as well as management experience. In addition, one expert did not return back the questionnaire and take part in the study. As a result, the Delphi investigation was considered as having limitation for arranging sound action plan that fits many HEIs in the country.

\subsection{Significance of the Study}

This study can be significant in the following ways:

1. It could contribute towards providing valuable information about the challenges and prospects of inclusive tertiary education of students with $\mathrm{VI}$ at AAU, increasing the awareness of the community about the particular areas for intervention.

2. The study may provide AAU with a practical and context-appropriate action plan in order to improve its inclusive policies and practices for the maximum benefit of students with VI over the next five years.

3. The study will add to the body of knowledge of the transformation of tertiary institutions into fully inclusive institutions, which might at the same time foster a change of attitude from one model of thinking to another.

4. The study could also serve as a source for other researchers conducting studies about other categories of impairment and levels of inclusive schooling.

\section{Review of Related Literature}

\subsection{Introduction}

In this chapter inclusive education is discussed in terms of theoretical and legal frameworks in order to place this study in a conceptual context. It is also necessary to consult the prior literature concerning the challenges and prospects of inclusive education in relation to students with VI in the context of tertiary education.

\subsection{Inclusion}

The most appropriate definition of inclusive education for this study is that it is the practical application of the theoretical and legal concept of inclusion. Inclusion in this sense acknowledges the rights of students with impairments to education and the need to reduce barriers that hinder their learning and participation in all aspects of higher education (Booth \& Ainscow, 2002:3 [8]; Walton \& Lloyd, 2012:64 [9]). Inclusive education refers to the full participation or incorporation of students with significant impairments into the general academic programs of HEIs irrespective of their impairments (Booth \& Ainscow,
2002:3 [8]; Claiborne, Cornforth, Gibson \& Smith, 2011:515 [10]; Connor, Gabel, Gallagher \& Morton, 2011:445 [11]; Sapon-Shevin, 2007:14 [4]). Inclusive education is becoming an appropriate approach in most African countries to involve students with impairment in educational settings and to allow access to the curriculum as full-time members of age-appropriate inclusive classrooms (Ainscow \& Sandill, 2010:401 [12]; Berlach \& Chambers, 2010:530 [13]). In the Ethiopian context, inclusive education refers to a new education system that is open to all learners, including learners with impairments, and requires the identification and removal of barriers that hinder learning and participation in schools and HEIs (MoE, 2006:3 [5]; Tirussew, 2005:118-119 [14]). Even though inclusive education is a challenging process for both Ethiopian schools as well as higher education institutions, it is becoming a legal and logical commitment to address disability issues (Tirussew, 2005:108,116). [14] As inclusive education has philosophical and practical components (Peters, 2007:99) [15], more attention has been given to practical ones like the inclusion of learners with impairments, as well as the broad social contexts within which inclusive policies and practices are implemented (Ballard, 1997:243).[16] Inclusive education recently serves as a prompt for managers to evaluate the system, physical conditions, as well as the capacity of human resources at their institutions with the aim of including all learners and meeting their particular needs (Tirussew, 2005:115).[14] To this end, the leaders of these institutions should examine their overall inclusive policies and practices in light of the appropriate theoretical and legal frameworks. For this reason, the existing paradigms and theories as well as their educational implications on the inclusion of students with VI in HEIs are discussed in the next section.

\subsection{Discourses on Inclusive Education}

The practical applications of inclusive education in different countries are varied as to the paradigms and theories they adopted in their institutions. Therefore, higher education institutions should choose paradigms and theories that are appropriate to their contexts in order to maintain effective inclusive education for students with impairments, including students with VI.

\subsubsection{Paradigms and their Practical Implications in Inclusion}

The political and social nature of inclusion should be understood in light of the paradigms that shape the concept of inclusivity (Ballard, 1997:245 [16]; UNESCO, 2001: 21 [17]). Being a guide to our world view, paradigms influence the attitudes and actions of people concerning disability issues and services needed. Therefore, the medical model social model, critical disability theory, and Vygotsky's learning theories were examined in order to understand the 
need for a holistic change in higher education regarding the support for students with VI.

\section{a) The Medical Model}

The medical model, (also known by different names such as deficit model or individual view), is the traditional model of disability that focuses on the impairments of people with disabilities and explains the difficulties they experience in their education in terms of those impairments (Mangal, 2007:5 [18]; UNESCO, 2001:21 [17]). The medical model tries to explain educational difficulties and poor academic achievement in terms of students' characteristics or deficits, without considering the wider environment, such as the social and political contexts in which they occur (Ballard, 1997:244 [16]; McCarthy \& Hurst, $2001: 4$ [19]; UNESCO, 2001:21 [17]). The medical model regards disability as a personal misfortune, and sees adapting to the environment as the responsibility of persons with impairment (UNESCO, 2001:21). [17] Since students with impairments are expected to cope with existing situations, no one, other than themselves, strives to make adjustments to the environment (Avramidis \& Skidmore, 2004:66 [20]; Powney, 2002:28 [21]). This kind of traditional understanding and reaction towards individuals with impairments is still evident in the policies and practices of some HEIs (Peters, 2007:99 [15]; Powney, 2002:28 [21]), including AAU. Therefore, this study examined the consequences of AAU's inclusive policies and practices emanated from the medical model of disability which neglects environmental factors. Since the medical model has often been considered as problematic and criticized for its emphasis on individuals with disability and total exclusion of social or environmental factors, it seems appropriate to shift towards the social model of disability (Rehabilitation Research Design \& Disability Centre, 2010:1-2). [22]

\section{b) The Social Model}

In the struggle of people with impairments for the acknowledgement of their right to full participation, the social model of disability was formulated with the aim of integrating people with impairment rightfully into an inclusive society (Sygall \& Scheib, 2005:30 [23]; UNESCO, 2001:21 [17]). Contrary to the medical model, the social model sees the whole educational system, rather than the impairment of the person, as a possible source of educational difficulties and poor academic achievement (Kinsella \& Senior, 2008:658 [24]; McCarthy \& Hurst, 2001:4 [19]; UNESCO, 2001:22 [17]). In other words, environmental barriers and the reactions of society towards people with impairments cause the real incapacitating circumstances in which people with impairments must function (Brown \& Boardman 2010:4 [25]; Kinsella \& Senior, 2008:658 [24]). From this perspective, the problem associated with VI, for instance, is seen as a product of a disabling and unresponsive learning environment and socio-political circumstances (Ballard, 1997:244[16];
McCarthy \& Hurst, 2001:4 [19]). To limit this unfortunate situation, universities should understand and remove the attitudinal and environmental barriers that students with impairments have to deal with in educational and social environments (Brown \& Boardman, 2010:4 [25]; Jacklin, Robinson, O'Meara \& Harris, 2007:47 [26]; UNESCO, 2001:22 [17]). The notion of shifting from the concept of individual pathology to organizational pathology is a central theme in the social model of disability and inclusive higher education (Gabel \& Peters, 2004:587 [27]; Kinsella \& Senior, 2008:658 [24]). Therefore, higher education institutions, including AAU, should make decisions based on the conceptual frameworks of the social model of disability when designing and adjusting the inclusive learning environment (Gabel \& Peters, 2004:587 [27]; Jacklin, et al., 2007:47 [26]; McCarthy \& Hurst, 2001:4 [19]). Having this concern in mind, the researcher used the principles of the social model of disability as a frame of reference to explore the challenges that students with VI face at AAU and their possible solutions.

This study also considered other theories, such as critical disability theory and Vygotsky`s learning theories, that are compatible with the social model of disability.

\section{c) Critical Disability Theory}

The critical disability theory adopts a version of the social model which explains disability as a social construct rather than the consequence of impairments (Hiranandani, 2005:6 [28]; Hosking, 2008:7 [29]). A critical theory can be distinguished from traditional theories because it seeks human emancipation and transforms the circumstances that enslave human beings (Bohman, 2012:1). [30] Unlike other critical theories, the critical disability theory refutes the medical model and strives for equality and inclusion (Hosking, 2008:17 [29]; Pothier \& Devlin, 2006:2, 9-10 [31]). As far as the critical disability theory is concerned, the vital question is not whether a particular person is disabled or not, but rather what society's response to the person's circumstances will be (Pothier \& Devlin, 2006:5). [31] The critical disability theory plays an advocacy role in challenging discrimination in terms of disability, gender, ethnicity, age and class (Goodley, 2013:641). [32] Therefore, critical disability studies pursue solutions that ensure the full inclusion and participation of people regardless of their differences. Transforming society with the objective of human emancipation is the primary purpose of the critical disability theory (Hosking, 2008:3).[29] Together with the aim of the present research, this includes an action agenda for reform that may change the lives of the students with impairments, as well as the nature of inclusivity of the institutions in which they learn or live (Creswell, 2003:9). [33] For this reason the researcher adopted the critical disability theory as the broad theoretical foundation of this study.

\section{d) Vygotsky's Theories of Learning}

This study focuses on Vygotsky's social theories, since 
they conceptualize disability as a social construct and emphasize the importance of transforming social and political contexts. Although the social model of disability and critical disability theory share this outlook, Vygotsky's social theories are important because they have been substantiated by empirical data accumulated for more than half a century and applied in various contexts to analyze the challenges to inclusion critically, and to identify intervention strategies that could remove those challenges (Kozulin, Gindis, Ageyev \& Miller, 2003: 217). [34] With this in mind, the researcher adopted both the socio-cultural and mediated learning theories of Vygotsky in order to identify the socio-cultural challenges of students with VI and to determine possible forms of intervention.

\section{i) Socio-cultural Theory}

Vygotsky is one of the most prominent social theorists who formulated the socio-cultural theory that claims the social, cultural and historical forces all play a part in human development and initiate the creation of appropriate methodologies and interventions (Daniels, 2001:7). [35] According to Vygotsky, the fundamental prerequisite of pedagogies demands individualization that suggests responsiveness to diversity rather than the burden of 'sameness' in learning and development (Daniels, 2001:99). [35] The other basic philosophical principle of the socio-cultural theory is that learning takes place when the learner interacts with the socio-cultural environment (Daniels, 2001:7). [35] In this regard, Tirussew (2005:118) [14] argues that one of the reasons to shift towards inclusive education in Ethiopia is to achieve psychological, social, as well as educational interaction between students with impairments and their peers. According to Sacks, Kekelis and Gaylord-Ross (1992:32) [36], a variety of socio-cultural factors, such as activities, partners, settings and materials affect the frequency and quality of interaction between the learner and peers. On the other hand, the power of peer interaction strongly affects learners' long-time socialization (Sacks, Kekelis \& Gaylord-Ross, 1992:9). [36] By understanding the effects of these contextual factors on social exchanges, educators can create environments that foster positive interaction among students (Sacks, Kekelis \& Gaylord-Ross, 1992:21). [36] At AAU these contextual factors should be taken into account to prompt social interaction. Therefore, this study identified the major challenges facing students with VI when learning and interacting with peers within the socio-cultural contexts of AAU. It also recognized the intervention strategies that foster the inclusive learning and social interaction of students with VI within the socio-cultural arenas of AAU.

\section{ii) Mediated Learning Theory}

Similar to the socio-cultural theory, the meditational model entails the mutual interaction of individual and supra-individual factors such as social, cultural and historical factors (Daniels, 2001:1 [35]; Kozulin et al., 2003:17, 23 [34]) that should be considered when dealing with the inclusion of learners with VI in social activities. These factors lie at the heart of many attempts to understand the possibilities for intervention in human learning and development (Daniels, 2001:1 [35]; Kozulin et al., 2003:17, 23 [34]). Vygotsky's mediated learning theory attempts to provide an account of learning and development as a mediated process. Russian students of Vygotsky's theory researched two types of mediation, namely mediation through another human being and mediation in the form of organized learning activities (Kozulin et al., 2003:17). [34] Teachers (as human mediators) are responsible for establishing an interactive instructional situation in the classroom where learners are active participants and they use their knowledge to guide learning (Daniels, 2001: i). [35] Vygotsky describes tools as material or psychological devices as well as products of human, social, cultural, or historical activities for mastering mental processes (Daniels, 2001:17). [35] The tools in the case of this study include the electronic devices available to support learners with VI. Human mediation that does not involve tools does not help the learner to master more complex forms of reasoning and problem-solving. Therefore, the combination of mediating learning and tools plays a crucial role in solving educational problems (Kozulin et al., 2003: 211). [34] This is especially true of students with VI in AAU. Therefore, the researcher applied the principles of mediated learning theory, including mediation through human beings and tools, in order to realize active learning and mutual interaction between students with VI and social, cultural and historical factors at AAU.

\section{e) The Mutual Adjustment Model}

In addition to the above theories and models of disability, the researcher also applied the mutual adjustment model in this study, as it emphasizes the active participation of learners with VI on decisions concerning the provision of inclusivity at AAU. Since there is no general approach to dealing with the unique needs of all students, a flexible approach should be applied to meet the academic and social needs of students with VI in inclusive settings. To this end, the mutual adjustment model was developed by Shepherd in the United Kingdom with the purpose of meeting the real needs of students with VI with their permission and approval (Shepherd, 2001:11). [37] Shepherd [37] states "the underlying principle of this approach is that students with VI can negotiate with the staff members and sighted students about the accommodations and adjustments to be made by the institution in order to ensure the most effective inclusive learning environment and address their resource limitations and safety issues (Shepherd, 2001:12)." According to Shepherd (2001:12-13) [37], the mutual adjustment model incorporates several ways to accommodate the needs of students with VI in higher 
education institutions. Information-sharing is one of the ways in which this approach is translated into action. Another method could be to allocate sufficient or additional time to students with VI to attend classes, to read prepared materials, and to do assignments and examinations. In addition, the mutual adjustment model includes the design of alternative study activities and materials. This component can be met by allowing students with VI to use special equipment and assistive technologies. Another component of the model is communication, and communicating regularly with students with VI is seen as essential. Finally, the mutual adjustment model requires the allocation of money to buy specific equipment or to finance special services. With this in mind, the researcher adopted the mutual adjustment model as a guiding approach for the identification of accommodations or adjustments that are made available to students with VI in the university under study.

Recently, Ethiopian institutions of higher education have been advised to examine their inclusive policies and practices in light of legal frameworks set out both internationally and locally.

\subsection{Legal Frameworks for Inclusive Education}

With the aim of meeting the rights and entitlements of people with impairments and others, the United Nations member countries, including Ethiopia, have developed several international and national laws or conventions. The international conventions, in particular provide legal frameworks to understand and interpret the practical actions of UN member countries when dealing with disability-related issues (Peters, 2007:100). [15]

\subsubsection{International Laws}

The international conventions formulated during the 1990s demonstrated considerable advances in legal support for students with VI in terms of their educational needs (Shepherd, 2001:17).[37] Of those frameworks, the 1993 United Nations Standard Rules on the Equalization of Opportunities for Persons with Disabilities and the 1994 Salamanca Statement and Framework for Action on Special Needs Education have been used as basic sources to formulate local policies and legislation in Ethiopia and other UN member countries for the protection of the rights of people with impairments and to ensure their educational and social inclusion at all levels of education. The 1993 United Nations Standard Rules on the Equalization of Opportunities for People with Disabilities especially contributes significantly to mobilize resources to all people with impairments (United Nations, 1994:8, 10[38]; United Nations, 2007:3[39]). Peters [15] states the United Nations Standard Rules represent a definite move towards a social model of inclusive education, especially with respect to Rule 6 on the provision of equal education at all levels (Peters, 2007:104)." The purpose of this rule is to ensure that people with impairments are allowed to exercise the same rights and obligations as others. This rule also serves as an instrument for policy-making and actions to remove the barriers that prevent people with impairments from exercising their rights, as well as having full participation in the activities of their societies and organizations (United Nations, 1994:7).[38] The document of the United Nations Standard Rules on the Equalization of Opportunities for People with Disabilities generally mentions that "provision should be made to assist people with impairments with issues such as awareness-raising, support services, access to the physical environment, information, equal tertiary educational opportunities, employment, social security and income maintenance, culture, recreation and sports (United Nations, 1994:10-25)".[38] Attention is paid to these issues in the present study in the examination of the inclusion of students with VI at AAU.

The 1994 Salamanca Statement and Framework for Action on Special Needs Education was developed to uniquely set the policy agenda for inclusive education on a global basis (Peters, 2007:104 [15]; UNESCO, 1994:iii [40]). The concept of inclusive education was introduced worldwide through the Salamanca Framework (Nguyen, 2010:349) [41] in which institutions are meant to include everybody, celebrate differences, support learning, and respond to individual needs (UNESCO, 1994:iii). [40] The guiding philosophy that informs this framework is that schools should accommodate all learners, regardless of their physical, intellectual, social, emotional, linguistic, or other conditions, as well as reducing the drop-out rate that are common in many education systems (UNESCO, 1994:6,7). [40] In general the Salamanca Framework represents a worldwide consensus on future directions and guidelines applicable at national, regional, and international level. This framework reveals that "inclusion requires the articulation of a clear and forceful policy and legislation, an extensive program of orientation and staff training, the provision of the necessary support services, and adequate resources. In addition, changes to the curriculum, buildings, pedagogy, assessment and staffing are necessary to cater successfully for students with VI (UNESCO, 1994:21)." [40]

\subsubsection{National Laws}

The introduction of the United Nations Convention on the Rights of Persons with Disabilities offers new opportunities particularly to African countries to reconsider their domestic legal laws relating to disability rights (Reenen \& Combrinck, 2011:1). [42] For example, Ethiopia is one of the developing countries that endorsed and adopted the 1993 United Nations Standard Rules (Reenen \& Combrinck, 2011:12) [42] pertaining to the rights of people with impairments in its national constitution, as well as other legal frameworks such as the Education Policy and Special Needs Education Program Strategy.

The Ethiopian constitution was created in 1995 to provide legal frameworks for ensuring the overall rights and entitlements of its entire people (Federal Democratic Republic of Ethiopia, 1995:79).[43] In particular, the 
constitution of Ethiopia has included general rights for individuals with disabilities, and explicitly incorporated disability within a broad non-discrimination guarantee (Sygall \& Scheib, 2005:30).[23] Since the Ethiopian Constitution does not include specific legislation that encourages inclusive education, the new Education Policy and Special Needs Education Program Strategies have been developed to provide specific legislative statements regarding the education and inclusion of people with impairments. The Special Needs Education Program Strategy was developed in 2006 by the Ethiopian Ministry of Education with the aim of identifying and removing the prevailing barriers to the implementation of inclusive education (MoE, 2006:5). [5] This federal-level strategy shows the direction for providing access to inclusive education to all learners by identifying and removing existing barriers at all levels of schooling and higher education (MoE, 2006:1,2). [5] As a result, HEIs are expected to establish resource centers that support students with VI and their lecturers, and that provide students with Braille literature, reading and writing tools, and training on ICT applications (MoE, 2006:30). [5]

In conclusion, both the theoretical principles and legal frameworks discussed above have been used as the foundation to identify the prevailing challenges and intervention strategies that should be adopted by universities in order to ensure the rights and full inclusion of students with VI. If AAU and other HEIs do not respond properly to meet those requirements that are enshrined in international and local legal documents, their inclusive practices will be challenged. In fact, the actual realization of inclusive education at universities is being threatened by various barriers. Therefore, this research aimed at reviewing the challenges to inclusive higher education and finding appropriate solutions to the problems faced by students with VI based on the prior studies made worldwide.

\subsection{Challenges to Inclusive Higher Education}

The afore-mentioned theoretical and legal frameworks can be used by researchers to examine critically the sources and types of challenges that affect the educational and social inclusion of students with VI in higher education institutions, including AAU. According to existing literature, the challenges or barriers to inclusive learning can be explained simply in terms of unresponsive policies, badly-designed curricula, inappropriate methods of instruction and assessment, poorly trained teachers, as well as inaccessible physical environments or facilities (UNESCO, 2001:220). [17]

\subsubsection{Challenges Associated with Inclusive Policies}

One of the areas in which challenges are evident is the policies that HEIs implement for the inclusion of students experiencing impairments (Booth \& Ainscow, 2002:5).[8] Although inclusion has been adopted as an important educational policy on the basis of social justice and equality, it is not being satisfactorily implemented in several developing countries, probably due to the absence of clear and enabling institutional policies (UNESCO, 2010:1-2).[44]

\subsubsection{Challenges to Access Information and Inclusive Support Systems}

Even though the situation varies from university to university, students with impairments can face several barriers when they try to access information and support while learning and living at HEIs. The lack of commitment and reliable channels of information especially has become a serious challenge to the inclusion of students with impairments (Shevlin, Kenny \& Neela, 2004:50).[45] As the existing reality at some universities shows, the inaccessibility of support systems and adjustments and adaptations often challenges the inclusion of learners with VI (Taylor, 1997:62).[46]

\subsubsection{Lack of Curricular Accommodation}

The South African White Paper 6 indicates that one of the most significant barriers for learners at inclusive HEIs is the curriculum, including the content, the organization and management of lecture halls or lectures, the methods and pace of teaching, the time available to complete the curriculum and the learning materials and equipment used (Department of Education, 2001:31 [47]; Taylor, 1997:61 [46]). In particular, students with VI might experience difficulties when they are required to work with visual curricular materials presented as charts, diagrams and tables (McCarthy \& Hurst, 2001:13 [19]) that have not been adapted. In addition, the different learning styles of students with impairments have been largely ignored in higher education curricula (Smith, 2002:66). [48] In general, the lack of adjustment and adaptation to instructional strategies and assessment are found to be a major challenge for students with VI in inclusive higher education (Wray, 2002:9). [49]

\subsubsection{Lack of Resources}

Most of the challenges to inclusive higher education in developing countries are associated with the lack of resources resulted in the prevailing economic and developmental difficulties so that the implementation of effective inclusion remains an unrealistic goal (Ainscow \& Sandill, 2010:411). [12] It is evident, therefore, that the greatest barrier to the inclusion of students with impairments in those countries is a lack of human, material and financial resources (Ainscow \& Sandill, 2010:411 [12]; Claiborne et al., 2011:521 [10]). In particular, the shortage of well-prepared staff, inaccessible physical/material resources, as well as a lack of funding structures are the major challenges faced by students with VI in HEIs (Eleweke \& Rodda, 2000:2). [50]

The intention of the researcher to identify the challenges from prior empirical studies was to use them as a point of 
focus when undertaking the data collection processes for this study. Although the current study focuses on identifying the existing challenges of the inclusion of students with VI in AAU, it may not be considered as a final result unless associated solutions are outlined. Therefore, the next section explores the solutions suggested in previous studies with the aim of adapting them to the particular context of AAU.

\subsection{Possible Solutions for Removing Challenges to Inclusive Education}

With aim of addressing challenges to inclusion, the researcher explored the following solutions from the findings of previous studies. He felt that this information could inform this investigation and some ideas could be applied by AAU to remove the wide spread challenges facing students with VI.

\subsubsection{Enabling Policies and Legislations}

To achieve the provision of equal opportunities and full participation to students with VI in academic and other activities which take place from admission to graduation, there should be relevant and clear policy guidelines at both institutional and departmental level (Shepherd, 2001:18). [37] Ultimately, HEIs have to work on an access-to-success continuum by promoting policies that provide clear directions for addressing the diverse needs of learners with VI and providing solutions to their problems from admission to graduation (UNESCO, 2010:1). [44] In addition there should be the will to translate the directions of policies into concrete actions thereby successfully ensuring the full inclusion of students with VI (Amadio, 2009:293). [51]

\subsubsection{Accessing Support Services to Students with Visual Impairment}

It is clear that strengthening support services will enable inclusive HEIs to reduce barriers to inclusive learning at all levels and is imperative in meeting the unique needs of students with VI (Department of Education, 2001:29). [47] The types of support that should be considered are academic (e.g., access to information and tutorial support), emotional (e.g., commitment from family and partners, or co-operation with fellow students), and practical (e.g., help with academic tasks, housework, space to study, facilities, time and comfortable working arrangements) (McNicol \& Nankivell, 2001:34 [52]; Moreland \& Carnwell, 2000:181 [53]). In this regard, Avramidis and Skidmore (2004:67) [20] include the provision of a physical working environment (e.g., buildings), learning resources (e.g., adaptive materials), working arrangements (e.g., time for study) and technical support of IT technicians as important types of support. As far as academic support is concerned, both formal and informal support structures, including personal tutor support, support from lecturers in departments and teaching assistants, should be provided to students with VI (Jacklin et al., 2007:5[26]; Wray, 2002:6 [49]). Peer tutoring programs are also an easy and effective form of support (Meijer, 2001:31). [54]

\subsubsection{Modifying or Adapting the Curriculum}

It is reasonable to suggest that curricula should be flexible enough to accommodate different learning needs and styles (Department of Education, 2001:31). [47] Flexible curricula that are accessible to all learners, irrespective of the nature of their learning style, should be central to any attempts to accommodate diversity at HEIs (Ashman, 2010:67). [55] Hence, curricula need to be adapted to remove the barriers experienced by learners with VI and to ensure their full inclusion (Ashman, 2010:67 [55]; UNESCO, 2010:2 [44]). To this effect, HEIs should consider the needs of students with VI when designing the curricula of various programs (Powell, 2003:27). [56] As assistive technology and devices have been shown to help to minimize barriers for students with VI studying visual fields of specialization (Murr \& Blanchard, 2011:200,205) [57], HEIs should allow the students to join departments of their choice by adapting the content and delivery style of the subjects (Smith, 2002:64). [48]

\subsubsection{Adapting the Instructional Methodologies}

It has become very important to allow students with VI to take advantage of choices available in terms of instructional strategies or multiple methods and tools for inclusive learning (D`Andrea, 2012:15). [58] Co-operative teaching (team teaching), co-operative learning (peer tutoring), individual planning, collaborative problem-solving and flexible instruction are the five approaches used in effective inclusive education (Meijer, 2001:117-118). [54] In keeping with these propositions, Ashman (2010:668) [55] advises HEIs to consider innovative instructional approaches like co-teaching and peer- mediated learning, in order to remove the barriers that students with VI face.

\subsubsection{Adapting the Assessment Mechanisms}

Some of the barriers that students with VI encounter can be minimized by changing assessment procedures or by implementing alternative methods of assessment (Wray, 2002:8). [49] This can be achieved by adapting assessment formats to suit the needs of students with VI (Clayton et al., 2010:19). [59] Specifically, students with VI might require extra time for examinations (time and a half is the usual extension), an alternative format for exams (e.g. oral, Braille), a separate and distraction-free examination room, the use of computers or the use of specialized adaptive equipment or software like text readers (Concordia University-Access Centre, 2011:1. [60]

\subsubsection{Accessing Resources}

As access to resources is one of the key elements in ensuring equality of opportunities and quality of education for students with VI, HEIs should allocate adequate human, 
physical and financial resources to implement inclusive education successfully (ECA, 2009:9 [61]; Wray 2002:9 [49]).

\section{a) Human Resources}

Powney [21] states "either universities or individual departments should allocate appropriate human resources to provide varying levels of support to students with VI and to remove any challenges they might encounter in all aspects of higher education (Powney, 2002:5)." In order to achieve this, universities and departments should be resourced by appropriate staff members, such as lecturers, technicians, librarians, peer mentors, note-takers, student advisors, administrators, special education teachers, teaching assistants, paraprofessionals and local service agencies to provide relevant support to students with VI (Orsini-Jones, 2009:32 [62]; QAA, 2010:26 [3]). It is also important to use paraprofessionals, such as peer mentors and individual assistants, to provide students with VI various forms of special support, including assistance in daily activities, safety and access to the environment and materials (Clayton et al., 2010:27). [59] In order to orient staff at all levels and raise their awareness, it is important for senior managers of HEIs to invest time and financial resources in relevant staff development programs (Shepherd, 2001:15). [37]

\section{b) Physical Resources}

Both research and best practice have shown that students with VI should have equitable access to the physical resources of HEIs in which they study, learn, live and participate. This includes access to physical environments like buildings, facilities and equipment (Tertiary Education Commission \& Ministry of Education, 2004:30). [63] Public buildings, and sanitation facilities should be made accessible to all students and the inclusion of steps and other design features should not make movement difficult for students with VI. More importantly, students with VI should be able to access physical facilities like cafes and other social spaces, as well as toilets without unnecessary difficulty (ECA, 2009:17). [61] In order to make buildings welcoming, comfortable, accessible, attractive and functional, special attention should be given to the design and development of entrances and routes of travel, furniture and fixtures. For example, classrooms should have clear directional signs and doors with sensors that can open automatically for the blind (Burgstahler, 2009:2). [64]

The provision of adaptive material and specialized technology is also vital for students with VI to overcome some of the challenges they experience (D'Andrea, 2012:2). [58] For example, the difficulties students with VI have when trying to work with visual or written texts, charts, diagrams and tables can be resolved through common adaptive materials, such as sound recorders, Braille writers, Braille transcribers, raised line paper or other tactile cues, abacuses, talking graphing calculators, and victor reader streams (Clayton et al., 2007:20 [59]; Concordia
University-Access Centre, 2011:2 [60]). Various reports claim that the use of a wide variety of specialized technology has had a significant impact on the learning and lives of students with VI (D'Andrea, 2012:2). [58] It has become critically important to provide students with VI with as many special devices and technologies as possible in order to enable them to access specially designed electronic resources like textbooks and curricular materials (D'Andrea, 2012:15). [58] For many students with VI computers are basic tools to access the printed publications in alternative formats, including Braille and electronic text (Burgstahler, 2009:3). [64] By accessing e-texts using a screen-reader, in which the information on the screen is voiced electronically by means of a speech synthesizer or using a printer that has Braille display, students with VI can have easy access to learning materials (Powell, 2003:21,43). [56]

\section{c) Financial resources}

Since the inclusion of students with VI requires specialist human and material resources, a well- structured funding arrangement is desirable to meet the needs of those learners. At a general level, special funds should be allocated from the university to maintain a variety of projects, such as the setting up of departmental support, production of adaptive or electronic learning materials, and so on (Avramidis \& Skidmore, 2004:79). [20] It is also crucial to specify the amount of money that the university provides for the procurement of necessary facilities and materials, and the hiring of personnel to support students with VI (Eleweke \& Rodda, 2002:117-121). [65] As Concordia University-Access Centre (2011:2) [60] argues, even though students with VI might be responsible for engaging their own assistants like readers and tutors as well as purchase specialized equipment and the necessary consumables, the university should arrange to pay for these services through student funding programs. Most importantly, rules and regulations of HEIs should be in place to regulate responsibilities and to guard against misuse of financial resources (Eleweke \& Rodda, 2002:117). [65]

\section{Research Methodology}

This section identified the philosophical foundation and specific methods which form the overall design of this study.

\subsection{Philosophical Foundation}

According to researchers De Vos, Schulze and Patel (2005:3 [66]), Neuman (2007:42 [67]), there are three main paradigms used in academic investigation, namely the positivistic, interpretive and critical paradigms. The interpretive and critical approaches are the two fundamental paradigms that can be adopted in social science studies (Neuman, 2007:42). [67] Most researchers 
who use the interpretive paradigm adopt the view of social reality from the perspective of the participants being studied (Neuman, 2007:43). [67] In this paradigm the goal of research is to seek the participants' views of the situation being studied as they have a better and in-depth understanding of the context in which they live and work (Creswell, 2003:8). [33] In particular, the interpretive approach strives to understand and interpret social reality (inclusive education in the case of this study) in terms of its actors so that historical, social and cultural circumstances can be understood and interpreted from the participants' perspectives (Creswell, 2003:8). [33] Research within the interpretive paradigm often includes calls for action and reform on issues of social injustice (Creswell, 2007:24). [68] Accordingly, the researcher worked within an interpretive paradigm to examine and interpret thoroughly the current challenges of students with VI in the inclusive context of AAU from the participants' points of view. The researcher also found practical solutions to the challenges that will transform the situation at AAU.

Since the critical and interpretive paradigms share many features, and both seek to convert knowledge into action in order to address socio-political issues, the researcher used the critical disability theory as a philosophical foundation to this study too (Neuman, 2007:44). [67] Critical disability theory is used in this research to investigate the transformation of inclusive education and the lives of students with V I (Creswell, 2003:9). [33] The researcher applied the critical disability approach as a complementary theoretical foundation in his attempts to find ways to emancipate students with VI from existing academic, structural, financial, social and cultural barriers at AAU.

\subsection{Design of the Study}

\subsubsection{Qualitative Paradigm}

Unlike the positivist paradigms, the interpretive and critical paradigms are often used in qualitative approaches to study complex phenomena (Creswell, 2003:18). [33] Qualitative researchers often use the interpretive paradigm to frame their studies on societal issues that influence marginalized and excluded individuals like students with VI (Creswell, 2007:24). [68] In practical terms, the aim of the research and the nature of the research questions are critical for the selection of the research approach or methodology (Grut \& Ingstad, 2005:6). [69] Since the researcher started with research questions rather than hypotheses, this study is designed in the qualitative paradigm (Leedy \& Ormrod, 2001:101). [70] Qualitative research usually focuses on general research questions with the purpose of seeking a better and deeper understanding of complex situations by collecting extensive qualitative data and building theory inductively (Leedy \& Ormrod, 2001:101). [70] In particular, qualitative research can study the social processes or cases in detail in their socio-cultural contexts and interpret data from participants' points of view
(Neuman, 2007:88). [67] With reference to the present research, it can be said that more research of this kind is needed to gain a greater understanding of inclusive educational practices from the perspectives of various participants such as teachers, administrators and students in their natural settings. For these reasons, the researcher applied the qualitative approach in this study since he sought to gain an in-depth understanding of the actual inclusion of students with VI in the social and educational contexts of AAU from the participants' perspectives. In addition, if a problem under investigation is relatively new, it merits a qualitative approach (Creswell, 2003:22 [33]; Neuman, 2007:16 [67]). This study was also qualitative because it studied the implementation of inclusive education, a relatively new trend in Ethiopia, and because its practical consequences in HEIs were mainly unexplored. This qualitative study specifically applied two particular methods, namely case study and Delphi survey because the researcher believed they could be instrumental in finding answers to the research questions posed.

\section{a) Case Study}

One of the typical designs of qualitative research is case study (Creswell, 2007:35). [68] A case study is an empirical investigation that examines a current phenomenon (inclusive education in the case of this study) in detail and in its real life context (Yin, 2009:18). [71] In practical terms, a case study can be used to investigate common cases, including individuals, organizations, processes, programs, institutions and even events (Yin, 2009:17). [71] Case studies can be applied in evaluation research to describe the real life contexts in which something has occurred as well as to explore intervention strategies (Yin, 2009:20). [71] Yin [71] states, "the case study method clarifies how a set of decisions have been taken to improve the situations being investigated (Yin, 2009:17)." Accordingly, the researcher adopted the case study method, especially the single-case design, as the preferred method to evaluate the current inclusive policies and practices of AAU with the purpose of seeking a deeper understanding of the challenges those students with VI face and the remedial decisions that should be taken to overcome the challenges.

The rationale for the selection of a single-case study design to this research is that it enabled the researcher to make an in-depth examination of the inclusion of students with VI only.

\section{b) Delphi Method}

The researcher applied the Delphi method as a complementary method to that of the case study as it enabled him to collect richer data that could lead to a deeper understanding of the primary research question of this study (Okoli \& Pawlowski, 2004:18).[72] The other advantage of Delphi research is its flexibility and potential to solicit a great deal of information from a group of experts in the area being investigated (Okoli \& Pawlowski, 2004:18).[72] In addition its flexibility to collect both 
qualitative and quantitative data that can address many research questions provided further impetus for selecting the Delphi method in this study (Okoli \& Pawlowski, 2004:18).[72] Besides, the researcher believed that the Delphi method could be a useful process to forecast future directions in the promotion of inclusive higher education of students with VI (Putnam, Spiegel \& Bruininks, 1995:2).[73] In particular, Delphi method can be applied to investigate feasibility of budget allocations, policy options and curriculum development at universities by structuring group communication among experts in a panel (Turoff \& Linstone, 2002:3).[74] Green [75] also says "it is useful for educational research focusing on planning, curriculum development, learning experiences and trends in higher education (Green, 2014:2)." Accordingly, the Delphi method was used in this study to forecast future support measures for students with VI at AAU, and then to generate an appropriate action plan based on the opinions of a group of experts who have expertise and qualifications in inclusive education. Besides, literature study was undertaken to determine challenges and possible ways in which students with VI could best be supported in higher education. The underlying reason for employing multiple methods is to ensure methodological triangulation and trustworthiness of the results of this study.

\subsection{Research Methods}

In most cases, research design involves specific research methods and procedures for implementing the processes of site and sample selection, data collection and data analysis or interpretation of findings (Teddlie \& Tashakkori, 2009:21). [76] The way each of these processes was applied is discussed below.

\subsubsection{Sampling}

The typical way of selecting sites and participants in qualitative research is by means of purposive sampling (Teddlie \& Tashakkori, 2009:25). [76] The purposive sampling technique is found to be effective in qualitative case studies (Creswell, 2003:185). [33] Purposive sampling is a strategy in which the researcher deliberately selects particular sites and participants in order to solicit the needed information to better understand the problem under investigation or to answer the research questions posed (Creswell, 2003:185). [33] Therefore, the researcher deliberately chose AAU which is the oldest and largest university in Ethiopia to be the site of this study. As it was established in 1950, it has a long-standing history of enrolling students with VI. The researcher purposively selected this university as the research site because most students with VI have recently chosen to study there. In the 2012-2013 academic years, for example, AAU had approximately 16,000 under-graduate students, of which 203 were students with VI. Conversely, there were only 59 students with hearing impairment and 86 students with physical impairment enrolled at the same time.

Qualitative researchers often use purposive sampling to select participants from the total population of a study (Teddlie \& Tashakkori, 2009:22). [76] who can provide sufficient and relevant information on the phenomenon under investigation (Grut \& Ingstad, 2005:9). [69] The particular issues to be considered in choosing participants are their unique ability to be informative or privileged witnesses to the topic of the study, as well as their experience and qualifications in the subject area of the investigation. As this is a qualitative study, the researcher drew participants from a number of sectors in the overall population of AAU. Thus, the researcher purposively included a group of students with VI, lecturers and managers together with a panel of Delphi experts. In addition considering the experience and knowledge of the socio-cultural settings of the potential informants, the researcher took their personal characteristics such as level of education and gender into account in his selection of participants (Grut \& Ingstad, 2005:7, 9). [69] Having this in mind, eight students with VI (four females and four males) were selected from five types or batches of admission for a group interview. After the group interview had been conducted, two students with VI (one female and one male) who had been more informative than the others were selected for individual interviews. In addition to the students, two lecturers (one female and one male) and three decision-makers (one department head, one college/faculty dean and one dean of student affairs) were selected purposively to participate in individual interviews. The researcher selected the interviewees based on their personal characteristics and experiences to answer the first three secondary research questions.

As far as Delphi questionnaire is concerned, the researcher found the purposive sampling technique more appropriate to select a relatively small number of participants or panel of experts to complete the Delphi questionnaires (Mc Nicol \& Nankivell, 2001:37). [52] The reason for consulting experts was that it was felt that an expert with a $\mathrm{PhD}$ in special needs education would have sufficient knowledge of what makes inclusive education effective. The researcher needed to garner expert opinions in order to develop an action plan for AAU to make its resources and services accessible to students with VI (Okoli \& Pawlowski, 2004:250). [72] To this end, the researcher purposively selected seven experts among 11 professionals who had PhDs in special needs education and served students with VI for a long period of time. They were involved in the study as respondents of the successive Delphi questionnaires.

\subsubsection{Data Collection Methods}

Data collection methods in qualitative research include observation, interviews, documents and/or audio visual materials (Creswell, 2003:185). [33] As this study is qualitative in nature, the researcher used a set of 
open-ended interviews for the case study and semi-structured questionnaires for Delphi investigation.

\section{a) Interviews}

An interview is one of the most important data collection methods in qualitative case studies (Yin, 2009:106). [71] Interviews using open-ended questions were used in this study to collect qualitative data from different respondents. The advantage of open-ended questions is that questions of special interest can be pursued in-depth and with great confidence. Therefore, the researcher developed a set of open-ended questions that he used while conducting interviews with participants in order to gather in-depth information from their real-life experiences. As Grut and Ingstad (2005:7) [69] indicate, an individual interview and a group interview (a focus group interview) can be applied to collect qualitative information either alone or in combination. If more details about the particular phenomenon (challenges in the case of this study) are desired, the researcher can conduct individual interviews. Accordingly, the researcher conducted a group interview with a group of eight students with VI using open-ended and semi-structured questions. In addition, individual interviews were conducted with different samples including students with VI, lecturers, department heads and deans to gather in-depth qualitative data. Each interview was conducted face-to-face between the researcher and one respondent at a time with the help of open-ended questions consisting of key themes or words (Grut \& Ingstad, 2005:6). [69]

\section{b) Semi-structured Questionnaires}

Researchers who apply the Delphi method typically use a series of questionnaires which seek judgmental information from participants without having direct contact with them (Okoli \& Pawlowski, 2004:16). [72] The researcher can use open-ended and semi-structured questions in the questionnaires to collect qualitative data from selected experts (Grut \& Ingstad, 2005:10). [69] Having this in mind, the researcher developed semi- structured questionnaires that consisted of closed and open-ended questions to collect qualitative and categorical data from Delphi experts about the phenomenon under investigation (e.g., the practicality of support measures and needed resources) with least expense. All in all, the researcher developed two rounds of semi-structured questionnaires and administered consecutively to Delphi experts in paper-pencil format in order to obtain their views and opinions on questions that addressed the primary as well as the last three secondary research questions of this study.

\subsubsection{Data Analysis}

Since large portions of qualitative data were collected by conducting a series of interviews and Delphi questionnaires, the researcher then applied an inductive approach to categorize and analyze the data in the light of the research questions posed. Specifically, the data collected through interviews are presented in line with the research sub-questions and topics generated during the data analysis. Comparisons were also made between the responses of informants and the findings from the literature study. Broad themes were inductively identified during the data analysis. The responses of the Delphi participants to the questionnaires were also grouped together to form categories based on the importance and practicality of each support measure included in the action plan. Eventually the researcher prioritized the support measures based on the consensus obtained from Delphi participants and refined the action plan for AAU to progressively increase the support of students with VI over a period of five years.

\section{Interpretation of Data and Findings of the Study}

\subsection{Interpretation of Data from Interviews}

As the study is qualitative in nature, the raw data obtained from different groups of interviewees were categorized and analyzed in order to identify the existing challenges that students with VI face at AAU and their possible solutions together with the necessary resources for supporting the students. Comparisons of findings were made while interpreting the data obtained from individual interviewees or group of interviewees. In addition, the common views of interviewees were contrasted with the prior findings obtained from the literature study. The main reason for making such comparisons was to triangulate the data from different sources so as to maintain the trustworthiness or validity of the findings from this research. With this in mind, the researcher first interpreted the data obtained from various interviewees about the challenges that students with VI face at AAU and then drew findings in order to answer the first secondary question of this study.

\subsubsection{Challenges that Students with VI Face at AAU}

As mentioned in the literature review section, the models and theories of disability as well as the international and local laws, all acknowledge that disabling and unresponsive physical, political, social and cultural environments can be the source of challenges for inclusive learning of students with VI at HEIs. Similarly, the findings drawn from the responses of interviewees in this study indicated that the existing physical, political and social circumstances of AAU were the source of various challenges faced by students with VI in terms of their inclusive learning and social interactions. The researcher specifically summarized the main findings in order to answer the first secondary research question of this study. Thus, the following table indicates the major challenges that students with VI face at AAU. 
Table 1. Challenges that Students with VI Face at AAU

\begin{tabular}{|c|}
\hline Chall \\
\hline $\begin{array}{l}\text { 1. Challenges outlined by student participants: } \\
\text { Lack of clear and suitable policies and regulations for the inclusion of students with VI; } \\
\text { Absence of practical responses in establishing supportive offices for ensuring equal opportunities of students with VI; } \\
\text { Inability to make special arrangements in terms of an inclusive environment as staff members considers the cause of problems to be the } \\
\text { impairment of students with VI; } \\
\text { Allowing students with VI to join only a few departments/programs in the social science field without considering their choices; } \\
\text { Inaccessibility of general and academic information in alternative formats other than writing; } \\
\text { Lack of well-organized support structures and services owing to the negative attitudes of staff members towards the inclusion of } \\
\text { students with VI; } \\
\text { Absence of adequate experts at the disability centre to properly support students with VI; } \\
\text { Absence of responsible bodies to provide students with VI with orientation and training in how to find classes and offices; Inaccessibility } \\
\text { of adapted curricular materials in different ways other than in printed format; } \\
\text { Lack of adaptations to instructional strategies to meet the needs of students with VI; } \\
\text { Lack of adaptations and interventions for continuous and summative assessment of students with VI; } \\
\text { Inadequate allocation of funds for readers, inappropriate examination venues and absence of time extensions for assessments affecting } \\
\text { the performance of students with VI; } \\
\text { Lack of counselors, knowledgeable and positive lecturers and personal assistants to support students with VI; } \\
\text { Inaccessibility of buildings, their fixtures and pathways for students with VI; } \\
\text { Unavailability of adequate and variety of adapted educational materials and supportive technology, as well as training in their use; } \\
\text { Inadequate funding for students with VI to cover their additional expenses; } \\
\text { Assigning students with VI to separate dormitories, recreational centers and dining rooms owing to their impairment; Difficulty of } \\
\text { students with VI to obtain support from sighted students as a result of their differences in religion and ethnicity; Sexual harassment } \\
\text { specifically of female students with VI. }\end{array}$ \\
\hline $\begin{array}{l}\text { 2. Challenges outlined by lecturer participants: } \\
\text { Absence of information about legal frameworks and theoretical principles that inform lecturers about inclusion of students with VI; } \\
\text { Failure to inform academic staff about the existing rules and regulations of university legislation that govern inclusive education; Lack of } \\
\text { knowledge about the appropriate disability model that lecturers should apply for handling students with VI; } \\
\text { Inability of students with VI to see the visual delivery of courses limiting their admission to the majority of the fields of study; Inability } \\
\text { of lecturers to adapt their teaching methods to support students with VI in special ways; } \\
\text { Difficulty of students with VI to write senior essays by referring them only to the available written materials; Conducting only written } \\
\text { assessments owing to the absence of incentives and additional resources for lecturers; Complaints by lecturers about the dishonesty of } \\
\text { examination readers; } \\
\text { Invigilation of students with VI in corridors with no time extension; } \\
\text { Lack of training and orientation of staff members about how to address the problems of students with VI; Difficulties in the use of } \\
\text { buildings and roads on the campus experienced by students with VI; } \\
\text { Failure to provide adaptive curricular materials and technology for students with VI and their lecturers. }\end{array}$ \\
\hline $\begin{array}{l}\text { 3. Challenges outlined by senior manager participants: } \\
\text { Absence of special rules and regulations focusing on students with VI; Lack of communication with staff about university legislation; } \\
\text { Absence of binding regulations and financial support for lecturers to access information in alternative formats other than writing; } \\
\text { Reluctance to assign students with VI to departments of their choice; } \\
\text { Treating students with VI in the same way as sighted students without taking their special needs into account; } \\
\text { The failure of disability centers to effectively support students with VI and their lecturers owing to the shortage of adequate experts and } \\
\text { funds; } \\
\text { Absence of mobility orientation and training for students with VI; Lack of knowledge and skills on how to teach students with VI; } \\
\text { Lack of adjustment to the times, places and modalities of assessments to students with VI; } \\
\text { Failure to set out a system that alleviates the conflict between lecturers and students with VI on the responsibility of providing } \\
\text { examination readers; } \\
\text { Absence of peer-tutors and inability of lecturers to properly support students with VI; } \\
\text { Failure of departments and disability centers to supply adaptive materials and training on how to use them; Absence of specific funding } \\
\text { for students with VI at department and faculty level. }\end{array}$ \\
\hline
\end{tabular}

In brief, all groups of informants of this study commonly noticed that students with VI encountered the following nine big challenges when learning and living in AAU. Firstly, the absence of clearly stated and enabling policies is a potential challenge to students with VI in AAU. Secondly, as the majority of staffs in AAU did not have awareness and knowledge on social model of disability and associated theories, they assumed the impairment that students with VI have is a source of difficulties regardless of the social and structural attributes so that they often required students with VI to cope with the existing situations at AAU instead of adjusting them in favor of the students. Thirdly, AAU did not allowed students with VI to join departments available in sciences and technology streams other than a few programs in social sciences and humanities as a result of wrong philosophical perceptions and reactions of staffs. Fourthly, inaccessibility of general and academic information in alternative formats was a critical challenge that students with VI have facing in AAU. Fifthly, the absence of well-organized support structures was the other serious challenge for students with VI that make their living and learning difficult at AAU. Sixthly, 
the absence of curricular adaptations was one of the unique challenges that students with VI faced in AAU. Seventhly, students with VI further experienced a variety of challenges in terms of teaching methods, learning styles, pace of instruction and classroom management since the majority of lecturers in AAU were not able and willing to adapt their instructional processes as to the needs of students. Eighthly, students with VI were also exposed for unexpected challenges due to the absence of assessment adaptations at AAU. Finally, it was found that most of the challenges that students with VI have experienced in AAU have direct connection with the shortage of well oriented or trained human resources, accessible physical or material resources and adequate financial resources. All in all, these results are significantly supported by the prior findings obtained from the literature study.

As stated earlier in Chapter 1, this study focuses on the identification not only of challenges but also possible solutions and necessary resources with the ultimate purpose of overcoming the challenges that students with VI face within the context of AAU. Therefore, the researcher presented suggestions of interviewees which they thought would overcome the challenges identified above.

\subsubsection{Major Findings in Respect of the Second and Third Secondary Research Questions}

The second and third secondary questions of this study informed the researcher to propose resources and solutions for overcoming the challenges that students with VI face in AAU on the basis of the data gathered from all participants in the student, lecturer and senior management groups. Therefore, the next table highlighted the general findings drawn from the suggestions forwarded by three groups of interviewees to be applied in the context of AAU.

Table 2. Solutions and Resources to Overcome the Challenges

\begin{tabular}{|c|c|}
\hline POSSIBLE SOLUTIONS & RESOURCES NEEDED \\
\hline $\begin{array}{l}\text { 1. Possible solutions forwarded by student participants: } \\
\text { Developing and implementing suitable regulations for students with VI; Adapting the environment and } \\
\text { facilities; } \\
\text { Providing training on how to use the technology; Assigning specialist experts and peer-tutors; } \\
\text { Providing training to lecturers on how to adapt their teaching approach and materials, as well } \\
\text { as assessment mechanisms; } \\
\text { Replacing senior essays with other modes of assessment; Supplying adequate monthly allowances to students } \\
\text { with VI; Assigning students with VI to ground floor classrooms; Making roads free from obstacles; } \\
\text { Providing posted information in alternative formats; } \\
\text { Assigning students with VI to departments of their first choice; Conducting discussions with students with VI } \\
\text { every four months. }\end{array}$ & $\begin{array}{c}\text { Assistive materials and } \\
\text { technology } \\
\text { Adequate financial resources } \\
\text { Experts in visual impairment } \\
\text { and in guidance and counseling } \\
\text { Accessible physical } \\
\text { environment }\end{array}$ \\
\hline $\begin{array}{l}\text { 2. Possible solutions forwarded by lecturer participants: } \\
\text { Developing clear policies that facilitate situations for students with VI and lecturers; Familiarizing the } \\
\text { performers about the rules and regulations set out to support and assess students with VI; } \\
\text { Providing orientation to management and academic staff about the rights of students with VI } \\
\text { as stated in international and local laws and theoretical frameworks; } \\
\text { Providing training to lecturers on how to teach and access lectures, assignments and examinations for students } \\
\text { with VI; } \\
\text { Providing training and orientation to university staffs and students with VI about inclusive education and how } \\
\text { to use assistive technology; } \\
\text { Adapting the curricular materials and facilities; } \\
\text { Substituting other courses for doing an essay or a research work if the inaccessibility of references in } \\
\text { alternative formats is continuing as usual; } \\
\text { Accessing written information for students with VI in softcopy and computers with JAWS } \\
\text { software; } \\
\text { Allocating sufficient funds for examination readers; } \\
\text { Assigning individual assistants to students with VI and their lecturers; } \\
\text { Providing support and counseling by psychologists and professionals in special needs education; } \\
\text { Assigning classrooms on ground floors of buildings for students with VI; } \\
\text { Conducting regular discussions with lecturers and administrative workers in order to change their negative } \\
\text { attitudes towards students with VI. }\end{array}$ & $\begin{array}{l}\text { Incentives to lecturers Experts } \\
\text { at disability centers and other } \\
\text { professionals Personal } \\
\text { assistants Adaptive materials } \\
\text { and technology Adaptive } \\
\text { curricula Additional funding } \\
\text { Accessible Classrooms }\end{array}$ \\
\hline $\begin{array}{l}\text { 3. Possible solutions forwarded by senior manager participants: } \\
\text { Developing and implementing a systematic policy or regulation to provide support and additional services for } \\
\text { students with VI; } \\
\text { Disseminating the information on inclusive policy and practices to students with VI and the wider university } \\
\text { community; } \\
\text { Providing training and orientation to all lecturers on how to treat students with VI and address } \\
\text { their needs; } \\
\text { Assigning professionals in visual impairment to departments where a large number of students with VI are } \\
\text { found; } \\
\text { Allocating reasonable funding for students with VI; } \\
\text { Providing easy access to the physical environment for students with VI; } \\
\text { Providing adaptive materials and assistive technology and training in their application. }\end{array}$ & $\begin{array}{l}\text { Knowledgeable lecturers and } \\
\text { professionals } \\
\text { Peers or personal } \\
\text { readers/assistants Adapted } \\
\text { materials and technology } \\
\text { Sufficient special funding }\end{array}$ \\
\hline
\end{tabular}


The afore-mentioned suggestions made by most participants from all groups are supported by the findings of prior studies discussed in the literature study section.

\subsection{Analysis and Findings of the Delphi Investigation}

Two-round Delphi questionnaires were successively conducted with Delphi participants to identify a prioritized list of support measures and types of resources by means of consensus obtained among the Delphi experts. Firstly, the researcher administered the first-round Delphi questionnaire to seven panel experts in person to obtain their views about the implementation time of the proposed support measures and the resources they needed. Of the participants, six experts returned the questionnaires by prioritizing the support measures and by marking their choices in the matrix of a five-year timeline. The researcher, then, fully represented the responses of Delphi participants about the priority of each support measure and the resources needed within the second round Delphi questionnaire (the final round in the case of this study). Finally, the second-round Delphi questionnaire that comprised the outcomes of the first-round Delphi questionnaire as feedback was presented to the Delphi experts to enable them to re-evaluate their responses, if they so wished, and to make final decisions on the implementation time of the support measures. As a result, the Delphi participants re-evaluated their prior answers by comparing them with the summarized responses of other participants to the first-round Delphi questionnaire. The researcher then compiled all the responses given by participants to the first and second-round Delphi questionnaires in order to answer the fourth secondary and the primary research questions of this study.

\subsubsection{Major Findings in Respect of the Fourth Secondary Research Question}

The researcher decided after a literature study that the
Delphi method could be an effective way to develop an action plan that comprises various support measures for students with VI. With the information at the researcher's disposal, the choice of the Delphi method was a good one to determine such a five-year plan based on a considerable consensus among Delphi experts with higher qualification and ample experience.

\subsubsection{Major Findings in Respect of the Primary Research Question}

The primary question of this study seeks the views of Delphi participants about the importance and practicality of each support measure in order to develop a five-year action plan aimed at overcoming the existing challenges and increasing the support for students with VI within the particular context of AAU. Therefore, the researcher obtained the views and opinions of Delphi participants about the importance and implementation time of the proposed support measures ( 81 in total) by means of two-round Delphi questionnaires. The Delphi participants helped ultimately to organize the plan of action into a five-year plan by deciding which measures were fundamental particularly for each year. The researcher then made a descriptive outline of a prioritized list of support measures and resources which obtained a considerable consensus among four and more $(\geq 66 \%)$ Delphi participants to be implemented over the next five years at AAU. On top of that, the support measures were grouped into major categories or themes, namely policies, admission, additional support services, adaptation of curricula, instructional strategies and assessment tools, as well as provision of adequate human, physical and financial resources. Thus, Table 3 illustrates the list of support measures and their categories as follows. 
Table 3. Support Measures to be Included within the Five Year Action Plan Of AAU for the Support of Students with VI

\begin{tabular}{|c|c|}
\hline CATAGORIES & SUPPORT MEASURES \\
\hline Policy & $\begin{array}{l}\text { Revise all policies, in line with the social model of disability. } \\
\text { Make institutional policies available to the wider university community. } \\
\text { Audit the impacts of existing institutional policies and revise them in consultation with students with VI. }\end{array}$ \\
\hline Admission & $\begin{array}{l}\text { Sort clear, supportive and flexible entry criteria into departments. } \\
\text { Supply information and counseling about fields of study to students with VI for making informed choices. Give } \\
\text { priority to students with VI to join the departments they choose. }\end{array}$ \\
\hline Support & $\begin{array}{l}\text { Provide guidance and counseling services by specialists. } \\
\text { Supply orientation and mobility training a week before the university opens. Accommodate students with VI in } \\
\text { dormitories with sighted peers for social interaction. Create opportunities for social contact with staff members with } \\
\text { VI. } \\
\text { Provide social interaction in class and on extra-curricular levels. Organize recreational activities. } \\
\text { Supply specialist support in the disability centre and departments by professionals. Encourage lecturers to provide } \\
\text { general academic support. } \\
\text { Appoint personal mentors (tutors or peers). }\end{array}$ \\
\hline Curricula & $\begin{array}{l}\text { Conduct regular discussions with students with VI to determine their needs. } \\
\text { Modify curriculum materials, such as syllabi, modules, course outlines, lecture-notes, handouts, worksheets and } \\
\text { assignments for students with VI in their preferred formats. } \\
\text { Adapt curriculum content and enhancing accessibility. }\end{array}$ \\
\hline $\begin{array}{c}\text { Instructional } \\
\text { Strategies }\end{array}$ & $\begin{array}{l}\text { Refer to and use references in alternative formats. Update the skills of lecturers. } \\
\text { Adjust instructional processes to suit students with VI. } \\
\text { Keep front row seats open for students with VI. Provide instructional material in alternative formats. Allow } \\
\text { recording of lessons. } \\
\text { Verbalize written notes. } \\
\text { Pace presentation according to time constraints of students with VI. } \\
\text { Let sighted volunteers assist students with VI during group work activities. Make timely arrangements for field trips. } \\
\text { Apply collaborative teaching and cooperative learning strategies. }\end{array}$ \\
\hline Assessment & $\begin{array}{l}\text { Make copies of handouts and assignments three weeks prior to submission to be available on time for Braille } \\
\text { transcription. } \\
\text { Allow extra time for students with VI to do assignments and examinations. Replace written examinations with oral } \\
\text { assessments. } \\
\text { Use assessments in alternative formats, including oral examinations. } \\
\text { Review the arrangements for assessments in collaboration with students with VI. }\end{array}$ \\
\hline Resources & $\begin{array}{l}\text { Assign adequate and skilled experts to the disability centre and departments. Make peer-tutors or mentors available } \\
\text { to students with VI. } \\
\text { Enable students with VI to hire personal assistants by using the university's financial resource. } \\
\text { Ensure that teamwork and collaboration between lecturers and other professionals is effective. Encourage } \\
\text { collaboration between disability-related associations and external institutions. } \\
\text { Offer general orientation and training to service providers. } \\
\text { Offer short-term training and pre-service or in-service teacher education to academic staff members. Adjust physical } \\
\text { environments and facilities to suit students with VI. } \\
\text { Make adapted materials and supportive technology accessible to students with VI. } \\
\text { Arrange seats and facilities in classrooms to ensure the safety and security of students with VI. Provide students with } \\
\text { VI with additional funds to buy and maintain assistive technology. Allocate adequate funds for students with VI and } \\
\text { the departments to which they are allocated. Devise incentive mechanisms for lecturers of students with VI. } \\
\text { Establish external funding streams with partners. }\end{array}$ \\
\hline
\end{tabular}

\section{Recommendations and Final Remarks}

\subsection{Recommendations}

As long as the existing challenges to students with VI are multi-dimensional in nature, their solutions and interventions need comprehensive and integrated efforts from all stakeholders at AAU. It is believed that the remedial actions will fully address the challenges if they are incorporated into the action/strategic plan of the university and implemented by all concerned bodies at AAU rather than by individuals not permanently involved at the university.

\subsubsection{Recommendations to University Management}

As the action plan emanating from this study is in line with basic international and national legal frameworks as well as the principles of the social model of disability and associated theories on inclusive education, it should ideally be implemented by University Management in their overall strategic plan to ensure the rights and equal opportunities of students with VI. In particular, the researcher recommends that AAU's top-level and senior leaders should firstly reform the existing institutional policies or legislations to be disability-specific and supportive of students with VI based on the action plan developed. Consequently, the leaders should regularly orient and enforce the line managers, lecturers and other service providers to act 
immediately in accordance with the action plan developed. Finally, the leaders must follow up and audit the implementation of the action plan and take immediate measures when they find it necessary to do so.

\subsubsection{Recommendations to University Lecturers and other Service Providers}

University lecturers and other service providers should undergo the necessary training concerning the paradigm shift, including measures incorporated in the action plan. They should carry out their duties and responsibilities accordingly, in order to improve their inclusive practices and progressively increase the support for students with VI over the next five years. While the inclusion of students with VI in higher education is a relatively new field, much information is still needed about the learning styles of students with VI, because they are not necessarily auditory learners only. Mediated learning fits how the lecturer can effectively teach learners with VI, as well as the art of adapting of learning materials deserves to be scrutinized. This study can be a valuable source that AAU should wish to implement the plan and keep abreast of international and national policy requirements. While the Delphi method is flexible and under-utilized in the context of AAU, professionals could investigate possibilities for using the Delphi method in their own circumstances in their further research about inclusive education and other related areas.

\subsubsection{Recommendations for Further Research}

Students with VI are currently learning in HEIs with little or no support from decision-makers and practitioners, because there are no well-organized support systems in place. This, in turn, causes a variety of challenging situations to students with VI and for them to be successful in their higher education studies. The typical strategies that have been applied in Ethiopian HEIs to address the issues of inclusion were merely undertaking conventional researches about the exploration of causes and types of challenges and their possible solutions. However, this study is valuable and unique, since it presents a well-structured action plan that can enable the university to react immediately towards the challenges facing students with VI. As most Delphi experts commented, the application of the Delphi method in this study is the first of its kind in the area of inclusive education that they are aware of, so that many local researchers will possibly adopt the methodology in their further research.

\subsection{Final Remarks}

It was apparent that the existing understanding and reaction of the university staff members towards the inclusion of students with VI was informed by the philosophy of the medical model rather than the social model of disability. As the staffs lack awareness on how to apply the principles of the social model of disability and its associated theories, they felt the cause of the students' problems is their visual impairment or incapability instead of making the necessary changes to accommodate such students. It is therefore essential to focus on the importance of training staff members from a social model of disability perspective. If this is not done, too many students will not realize their God-given potential. Furthermore, the action plan may contribute to other public and private universities who have similar circumstances as those at AAU. These universities can adopt it and improve their inclusive policies and practices or increase the support of students with VI in their own contexts.

\section{REFERENCES}

[1] Ainscow, M. and Sandill, A. 2010. Developing inclusive education systems: The role of organizational cultures and leadership. International Journal of Inclusive Education, 14(4): 401-416.

[2] Amadio, M. 2009. Inclusive education in Latin America and the Caribbean: Exploratory analysis of the national reports presented at the 2008 international conference on education. Springer Link, 39 (3): 293-305.

[3] Ashman, A. 2010. Modelling inclusive practices in postgraduate tertiary education courses. International Journal of Inclusive Education, 14 (7): 667-680.

[4] Avramidis, E. and Skidmore, D. 2004. Reappraising learning support in higher education. Research in Post-compulsory Education, 9 (1): 63-82.

[5] Ballard, K. 1997. Researching disability and inclusive education: Participation, construction and interpretation. International Journal of Inclusive Education, 1 (3): 243-256.

[6] Berlach, R. and Chambers, D. 2010. Interpreting inclusivity: An endeavour of great proportions. International Journal of Inclusive Education, 15 (5): 529-539.

[7] Bohman, J. 2012. Critical theory. http://plato.stanford.edu/ (Accessed 2013-02-04)

[8] Booth, T. and Ainscow, M. 2002. Index for inclusion: Developing learning and participation in schools. Mark Vaughan: CSIE.

[9] Brown, L. and Boardman, F. 2010. Accessing the field: Disability and the research process. http://go.warwick.ac.uk/ (Accessed 2013-01-03)

[10] Burgstahler, S. 2009. Universal design in education: Principles and applications. http://www.uw.edu/doit/ (Accessed 2009-11-17)

[11] Claiborne, L., Cornforth, S., Gibson, A. and Smith, A. 2011 Supporting students with impairments in higher education: Social inclusion or cold comfort? International Journal of Inclusive Education, 15(5): 513-527.

[12] Clayton, K., Poe, R., Piti, B. and Goodman, D. 2010. Educating students with visual impairments in Texas: Guidelines and standards. Texas: Texas Education Agency. 
[13] Concordia University- Access Center. 2011. Services for students with visual impairment. http://www.supportservice.concordia.ca/(Accessed 2011-07-21)

[14] Connor, D., Gabel, S., Gallagher, D. and Morton, M. 2012. Disability studies and inclusive education implications for theory, research and practice. International Journal of Inclusive Education, 12(5): 441-457.

[15] Creswell, J. 2003. Research design qualitative, quantitative and mixed methods approaches. $2^{\text {nd }} E d$. London: Sage Publications Inc.

[16] Creswell, J. 2007. Qualitative inquiry and research design: Choosing among five approaches. $2^{\text {nd }} E d$. London: Sage Publications Inc.

[17] D'Andrea, F. 2012. Preferences and practices among students who read Braille and use assistive technology. http://www.afb.org/ Accessed 2012-12-06).

[18] Daniels, H. 2001. Vygotsky and pedagogy. London: Routledge Falmer.

[19] Department of Education. 2001. Education white paper 6: Special needs education: Building an inclusive education and training systems. Pretoria: Sol Plaatjie House.

[20] De Vos, A., Schulze, S. and Patel, L. 2005. The sciences and the professions in research at grass roots for the social sciences and human service professions. $3^{\text {rd }} \mathrm{Ed}$. Pretoria: Van Schaik, pp: 3-26.

[21] Economic Commission for Africa (ECA). 2009. UN Convention on the rights of persons with disabilities: A call for action on poverty, discrimination and lack of access. http://lcdsouthasia.org/ (Accessed 2010-07-14).

[22] Eleweke, J. and Rodda, M. 2000. Enhancing inclusive education in developing countries: Including the excluded http://www.isec2000.org.uk/ (Accessed 2010-10-03)

[23] Eleweke, J. and Rodda, M. 2002. The challenge of enhancing inclusive education in developing Countries. International Journal of Inclusive Education, 6(2): 113-126.

[24] Federal Democratic Republic of Ethiopia. 1995. The constitution of the Federal Democratic Republic of Ethiopia. Addis Ababa: House of Federation.

[25] Gabel, S. and Peters, S. 2004. Presage of a paradigm shift? Beyond the social model of disability toward resistance theories of disability. Disability and Society, 19(6): 585-600.

[26] Goodley, D. 2013. Dis/entangling critical disability studies. Disability and Society, 28(5): 631-644.

[27] Green, R. 2014. The Delphi technique in educational research. Sage Open, (April-June): 1-8.

[28] Grut, L. and Ingstad, B. 2005. Using qualitative methods in studying the link between disability and poverty: Developing a methodology and pilot testing in Kenya. Oslo: SINTEF.

[29] Higher Education Relevance and Quality Agency. 2009. Addis Ababa University institutional quality audit report. Addis Ababa: National P. Press Plc.

[30] Hiranandani, V. 2005. Towards a critical theory of disability in social work. http://www.uwindsor.ca/ Accessed
2013-02-08)

[31] Hosking, D. 2008. Critical disability theory: A paper presented at the $4^{\text {th }}$ Biennial Disability Studies Conference, Lancaster University.

[32] Jacklin, A., Robinson, C., O`Meara, L. and Harris, A. 2007. Improving the experiences of disabled students in higher education. University of Sussex: The Higher Education Academy.

[33] Kinsella, W. and Senior, J. 2008. Developing inclusive schools: A systemic approach. International Journal of Inclusive Education, 12(5-6): 651-665.

[34] Kozulin, A., Gindis, B., Ageyev, V. and Miller, S. 2003. Vygotsky's educational theory in cultural context. New York: Cambridge University Press.

[35] Leedy, P. and Ormrod, J. 2001. Practical research: Planning and design. $7^{\text {th }}$ Ed. New Jersey: Merrill Prentice Hall.

[36] Mangal, S. 2007. Educating exceptional children: An introduction to special education. New Delhi: Prentice-Hall of India Private Limited.

[37] McCarrthy, D. and Hurst, A. 2001. A briefing on assessing disabled students. Liverpool: LTSN Generic Centre.

[38] McNicol, A. and Nankivell, C. 2001. User learning needs: A critical literature review. Centre for Information Research.

[39] Meijer, C. 2001. Inclusive education and effective classroom practices. Ostre Stationsvej: European Agency for Development in Special Needs Education.

[40] Ministry of Education. 2006. Special needs education program strategy: Emphasising inclusive education to meet the UPEC and EFA Goals. Addis Ababa: Ministry of Education.

[41] Mji, G., MacLachlan, M., Melling-Williams, N. and Gcaza, S. 2009. Realising the rights of disabled people in Africa: An introduction to the special issue. Disability and Rehabilitation, 31(1): 1-6.

[42] Moreland, N. and Carnwell, R. 2000. Co-opting learners: Addressing their learning support needs through a learning support needs questionnaire. Research in Post-Compulsory Education, 5(2): 173-190.

[43] Murr, C. and Blanchard, R. 2011. Perceptions of the visually impaired toward pursuing Geography courses and majors in higher education. Journal of geography, 110(5): 200-208.

[44] Neuman, W. 2007. Basics of social research: Qualitative and quantitative approaches. $2^{\text {nd }}$ Ed. Boston: Pearson Education Inc.

[45] Nguyen, T. 2010. Deconstructing education for all: Discourse, power and the politics of inclusion. International Journal of Inclusive Education, 14(4): 341-355.

[46] Okoli, C. and Pawlowski, S. 2004. The Delphi method as a research tool: An example, design considerations and applications: Information and Management, (42): 15-29.

[47] Opertti, R., Brady, J. and Duncombe, L. 2009. Moving forward: Inclusive education as the core of Education for All. Prospects, (39): 205-214.

[48] Orsini-Jones, M. 2009. Measures for inclusion: Coping with 
the challenge of visual impairment and blindness in university undergraduate level language learning. Journal Compilation, 24(1): 27-34.

[49] Peters, S. 2007. Education for All? A historical analysis of international inclusive education policy and individuals with disabilities. Journal of Disability Policy Studies, 18(2): 98-108.

[50] Powell, S. 2003. Special teaching in higher education: Successful strategies for access and inclusion. London: Kogan Page Limited.

[51] Pothier, D. and Devlin, R. 2006. Critical disability theory: Essays in philosophy, politics, policy and law. Toronto: UBC Press.

[52] Powney, J. 2002. Successful student diversity: Case studies of practice in learning and teaching and widening participation. Northern Ireland: Higher Education Funding Council for England.

[53] Putnam, J., Spiegel, A. and Bruininks, R. 2010. Future directions in education and inclusion of students with disabilities: A Delphi investigation. http://www.questia.com (Accessed 2010-01-04).

[54] Quality Assurance Agency. 2010. Code of practice for the assurance of academic quality and standards in higher education. Gloucester: Southgate House.

[55] Reenen, T. and Combrinck, H. 2011. The UN convention on the rights of persons with disabilities in Africa: Progress after 5 years. http://www.surjournal.org/ (Accessed 2011-04-05).

[56] Rehabilitation Research Design and Disability Centre. 2010. Universal design in education- FAC. http://www.access-ed.r2d2.uwm.edu/ (Accessed 2010-03-05).

[57] Sacks, S., Kekelis, L. and Gaylord-Ross, R. 1992. The development of social skills by blind and visually impaired students: Exploratory studies and strategies. New York: American Foundation for the Blind.

[58] Saint, W. 2004. Higher education in Ethiopia: The Vision and its Challenges, Journal of Higher Education in Africa, 2(3): 83-113.

[59] Sapon-Shevin, M. 2007. Widening the circle. Boston: Beacon Press.

[60] Shepherd, I. 2001. Providing learning support for blind and visually impaired students undertaking fieldwork and related activities. Cheltenham: University of Gloucestershire.

[61] Shevlin, M., Kenny, M. and Neela, E. 2004. Access routes to higher education for young people with disabilities: A question of chance? Irish Educational Studies, 23(2): 37-53.
[62] Smith, J. 2002. Learning styles: Fashion fad or lever for change? The application of learning style theory to inclusive curriculum delivery. Innovations in Education and Teaching International, 39(1): 63-70.

[63] Sygall, S. and Scheib, M. 2005. Rights and responsibilities: A guide to national and international disability-related laws for international exchange organizations and participants. USA: Mobility International/National Clearing House on Disability.

[64] Taylor, I. 1997. Developing learning in professional education: Partnerships for practice. London: St Edmundsbury Press Ltd.

[65] Teddlie, C. and Tashakkori, A. 2009. Foundations of mixed methods research: Integrating quantitative and qualitative approaches in the social and behavioral sciences. London: SAGE Publications Inc.

[66] Tertiary Education Commission and Ministry of Education. 2004. New Zealand code of practice for an inclusive tertiary education environment for students with impairments. http://www.achieve.org.nz/ (Accessed 2010-03-05).

[67] Tirussew, T. 2005. Disability in Ethiopia: Issues, insights and implications. Addis Ababa: AAU Printing Press.

[68] Turoff, M. and Linstone, H. 2002. The Delphi method: Techniques and applications. Reading MA: Addison Weslay Publishing Company.

[69] UNESCO. 1994. The Salamanca Statement and Framework for Action on Special Need Education. Spain: UNESCO.

[70] UNESCO. 2001. Open file on inclusive education. Paris: UNESCO

[71] UNESCO. 2010. Inclusive education. http://www.unesco.org/ (Accessed 2010-07-19).

[72] United Nations. 1994. Standard rules on the equalization of opportunities for persons with disabilities. UN General Assembly.

[73] United Nations. 2007. Overview of international legal frameworks for disability legislation. http://www.un.org/ (Accessed 2012-4-05).

[74] Walton, E. and Lloyd, G. 2012. From clinic to classroom: A model of teacher education for inclusion. Perspectives in Education, 30(2): 62-70.

[75] Wray, M. 2002. Modification of examination and assessment arrangements for disabled students: Additional support or added advantage? Manchester: Manchester Metropolitan University.

[76] Yin, R. 2009. Case study research: Design and methods. $4^{\text {th }}$ $E d$. London: SAGE Publications Inc. 